\title{
Preservation of the environment for a healthy quality of life
}

Marcos José Cavalcanti Leite Saraiva ${ }^{1}$

Sanitarians have proclaimed that environment and quality of life are closely intertwined for a long time, but, recently, this awareness has become more visible due to the proliferation of infectious diseases and the increased number of deaths caused by environmental degradation.

The aggression process against the environment started with the establishment of the large metropolitan areas, because the man has changed the ecosystem to ensure its own survival and provide comfort for itself. These transformations of the preexisting space for human habitation, in a disorderly manner, affected the characteristics of the Earth's surface by destroying a huge part of the plant coverage, thereby resulting in abrupt climate changes, as well as in contamination of soil, atmospheric air, sea water, rainwater, river water and groundwater.

The major causes of the degradation of the environment are the lack of environmental education and of sewage disposal, since we do not have the universalization of the services related to water supply, sanitary sewage, solid waste management and drainage.

The main impact on the public health resulting from the lack of sewage disposal is the onset of infectious and waterborne diseases. Therefore, despite being an essential element for sustaining life, the water can entail diseases such as amebiasis, giardiasis, gastroenteritis, typhoid fever, hepatitis and cholera when it is not drinkable.

Moreover, the water is a supporting player in the contamination by worm-associated diseases such as schistosomiasis, ascariasis, taeniasis and ancylostomiasis, besides enabling opportunities for the proliferation of vectors such as the Aedes aegypti mosquito, which is capable of transmitting dengue, Zika virus, yellow fever and chikungunya.

As long as the structural issues required for preventing infectious diseases and mitigating environmental risk factors are not duly addressed, all that remains for health professionals is to remedy these illnesses, which could be prevented or reduced with preventive medicine actions, such as, for example, availability of sewage disposal services, which is an obligation of the State.

Added up to this governmental negligence, we still see certain ignorance about the reflex of the profound implications of the lack of these services on the public health and on the preservation of the environment. The omission of public agencies is also highlighted by the unavailability of institutional campaigns to raise the population's awareness about the importance of the environmental conservation.

Therefore, we point out the bright initiative of the National Conference of Bishops of Brazil with the launch of the 2016 Ecumenical Fraternity Campaign, focusing on the right of everyone to sewage disposal services and on the discussion of public policies to ensure the integrity and future of the environment, The theme of the aforementioned campaign is "Common house, our responsibility".

Nevertheless, we warn that society also has a duty to contribute towards preserving the environment, in addition to requiring our governments to comply with the constitutional obligations for universalizing the sewage disposal services and providing quality health services.

${ }^{1}$ Companhia de Água e Esgoto do Ceará. Fortaleza, CE, Brazil. 